\section{UPCOMING Oceanography SPECIAL ISSUE TOPICS}

Vol. 23, No. 2, June 2010

Marine Renewable Energy

Guest Editors: Kerry Kehoe (National Oceanic and Atmospheric Administration [NOAA]), Ralph Lopez (NOAA), Ellen Ternes (NOAA), Elisa Chae (NOAA), Carleigh Trappe (NOAA), Benjamin Baron-Taltre (NOAA), MaryLee Haughwout (NOAA), Annette von Jouanne (Oregon State University), and Ted Brekken (Oregon State University)

Vol. 23, No. 3, September 2010 Celebrating 50 Years of the Intergovernmental Oceanographic Commission Guest Editors: Phil Taylor (National Science Foundation), Kathy Tedesco (NOAA), and Deborah Bronk (The College of William and Mary, Virginia Institute of Marine Science)

\section{Vol. 23, No. 4, December 2010} The Future of Satellite Oceanography Guest Editors: Eric Lindstrom (National Aeronautics and Space Administration) and Nikolai Maximenko (University of Hawai i)

Vol. 24, No. 1, March 2011 Philippine Straits Dynamics Experiment Guest Editor: Arnold Gordon (Lamont-Doherty Earth Observatory)

\section{Regular Issue Features}

The editorial staff also encourages unsolicited manuscripts on other oceanography themes for consideration and publication under the Regular Features banner.

\title{
Of Note
}

A change in magazine policy calls for all Oceanography articles, starting with the December 2009 issue, to be made available in PDF format online as soon as final proofing of the entire issue is complete. The new policy lifts the threemonth embargo previously imposed on online publication of feature articles. We anticipate that immediate access to the science published in Oceanography will benefit authors and broaden the magazine's impact.

In another move to improve Oceanography's impact, we are experimenting with providing online access to an article's graphics, at the author's request. For example, anyone can download from the Oceanography Web site (http:// www.tos.org/oceanography) a zipped figure file for the December 2009 article by Hansell et al. on "Dissolved Organic Matter In the Ocean: A Controversy Stimulates New Insights." The figures are available as low-resolution jpg files appropriate for display in a classroom presentation. In the future, we expect to share more graphics, links to additional relevant materials, and other supplemental information via our Web pages.

Also new on the Oceanography Web site is a page that provides information on how to put together a special issue section of the magazine. If you have a topic that you would like to see covered and are possibly interested in being a guest editor, check out http://tos.org/oceanography/special_issues.html.

At the same time we are implementing the above improvements, The Oceanography Society has increased the fees to publish articles not associated with the special issue section after two decades of staying the same. To offset the costs of publishing, instead of charging the small flat fee of $\$ 500$ for any article, large or small, there is now a graded scale. Starting with the June 2010 issue, the $\$ 500$ fee will remain for articles 1-5 pages long. Authors of articles that are 6-12 magazine pages will now be charged $\$ 1000$, and articles that are 13-18 pages will cost $\$ 1500$. If an article exceeds 18 magazine pages, a $\$ 100$ charge for each additional page will be added. Authors can request a waiver from TOS (email to info@tos.org) for all or part of the publication fee if they document their inability to cover the expense. We do not wish, in any way, to discourage submission of articles whose publication fees cannot be covered by an author's grant.

We are always interested in readers' input on how to improve this publication. Please send us your comments and ideas.

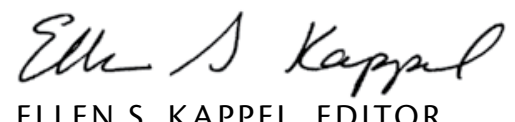

ELLEN S. KAPPEL, EDITOR 